\title{
ANTIBACTERIAL PROPERTIES OF COTTON FABRICS TREATED WITH 8-HYDROXYQUINOLINE AND BORAX
}

\author{
Banu Yeşim Buyukakinci ${ }^{1}$, Erdem Tezcan ${ }^{2}$
}

\begin{abstract}
Hydroxyquinoline (8HQ) is a metal chelating agent that also has antibacterial properties against several different bacterial specie, but its use in cotton textile fabrics has not been tested before. 8HQ may be an alternative to heavy metalbased applications for antibacterial textile fabrics therefore, the aim of this research paper was to investigate the antibacterial properties of $8 \mathrm{HQ}$ and borax (BX) treated cotton fabrics for the medical textile industry.

The homogenous distribution of the treated chemicals was confirmed with SEM/EDX imaging. The antibacterial activities of the fabrics were also tested against Escherichia coli and Staphylococcus aureus bacteria by mimicking the ISO 20645:2004 Standard Test Method.

The highest antibacterial property was observed with the $8 \mathrm{HQ}+\mathrm{BX}(8 \mathrm{HB})$ treated cotton samples. Therefore, the $8 \mathrm{HB}$ treated cotton products have a potential for use especially in the medical fields mainly due to the absence of heavy metals and bacterial growth.
\end{abstract}

UDC Classification: 604; DOI: http://dx.doi.org/10.12955/cbup.v6.1289

Keywords: Antibacterial, borax, cotton, 8-hydroxyquinoline

\section{Introduction}

8-Hydroxyquinoline (quinolin-8-ol) which is a white-yellow organic crystalline powder, is a small molecule with a lipophilic effect. 8HQ and its derivatives are also bidentate chelators that bind metal ions through the oxygen and nitrogen atoms (Block, 2012; Short et al., 2005). In addition to this, 8HQ is very effective against several different bacterial species including Staphylococcus aureus and Methicillin-Resistant Staphylococcus aureus (MRSA) (Srisung et al., 2013). Furthermore, because of the nontoxic properties of $8 \mathrm{HQ}$ and $8 \mathrm{HQ}$ derivatives, they can be used in the pharmacological and medicinal fields against, -cancer and HIV virus as anti-neurodegenerative agents (Prachayasittikul et al., 2013; Xie \& Peng, 2017; Xu et al., 2015).

Borax compounds are eco-friendly and are frequently used in sectors relating to glass, ceramics, agriculture and textile (De Seta et al., 2009; Yilmaz, 2012) as bleaching and reducing agents, and flame retardants (Buyukakinci et al., 2016; Buyukakinci \& Yilmaz, 2017). Their usage and importance in high-tech production also increases day by day.

Cotton is one of the best-known natural cellulosic fibers and it has been used since about $3000 \mathrm{BC}$. It is soft, strong, hypo-allergenic and easy to wash. The antibacterial cotton fabrics are used textile materials for clothing, medical and hygienic purposes (Klemencic et al., 2012; Reijnders, 2006). To give antibacterial properties, textile materials are treated with some chemical agents such as metals and metal salts, quaternary ammonium compounds, triclosan, chitosan, peroxyacids (Gao \& Cranston, 2008). However, there are concerns about these agents because of some limitations such as being heavy metals, irritants and harmful to the environment. Therefore, there is a need for cleaner alternatives.

The aim of this research paper was to investigate the antibacterial properties of 8HQ and borax treated cotton fabrics for the medical textile industry. 8HQ was chosen as an antibacterial agent and borax as an eco-friendly compound to increase the antibacterial effect of the $8 \mathrm{HQ}$. Therefore, $8 \mathrm{HQ}$ and borax treated cotton fabrics can be used as biomedical textile products.

\section{Experimental}

Materials: In the present study, $100 \%$ woven cotton fabric samples $\left(150 \mathrm{~g} / \mathrm{m}^{2}\right)$ were used in the treatments. 8-hydroxyquinoline (8HQ), borax (BX), sulfuric acid and sodium hydroxide were of analytical grade and were used as received.

\footnotetext{
${ }^{1}$ Department of Textile Engineering, Engineering Faculty, Istanbul Aydin University, Istanbul, Turkey, byesimb2@gmail.com

${ }^{2}$ Department of Nutrition and Dietetics, Health Sciences Faculty, Istanbul Gedik University, Istanbul, Turkey, erdemtezcan@gmail.com
} 
Cotton samples of $5 \mathrm{~g}$ were used throughout this work. All processes were carried out in $400 \mathrm{ml}$ glass beakers under atmospheric conditions. A TERMAL B21606E model washing machine was used for washing of the samples.

The chemical structure characterization was performed via a Perkin-Elmer BXII model FTIR spectrometer with an ATR module, with an average of 16 scans in the range of $400-4000 \mathrm{~cm}^{1}$.

Morphological properties and elemental composition of all samples were analyzed using the FEI Quanta 250 FEG 250 model scanning electron microscope with an EDX module.

Methods:

Bacterial Strains and Culture Media: The main cultures of E. coli (ATCC 35218) and S. aureus (ATCC 25293) were supplied from Microbiologics. The nutrient broth and nutrient agar and Trypticase Soy Broth and Trypticase Soy Agar culture media were supplied from Hi-media.

Preparation of the Treatment Solutions: Acidic and alkaline stock solutions of 8HQ were prepared by dissolving $20 \mathrm{~g}$ of $8 \mathrm{HQ}$ in $1 \mathrm{~L}$ of aqueous $0.1 \mathrm{M}$ sulfuric acid and $0.1 \mathrm{M} \mathrm{NaOH}$ solutions respectively at room temperature. Then the treatment solution was prepared using a borax solution according to Table1.

Table 1: Ingredients of the samples including their different types and final concentrations $(\mathrm{g} / \mathrm{L})$.

\begin{tabular}{|c|c|c|c|c|}
\hline Sample Code & $\mathbf{1 0 g} / \mathbf{L}$ 8HQ & $\begin{array}{c}\mathbf{1 0 g} / \mathbf{L} \text { Borax } \\
\text { Decahydrate }\end{array}$ & Acidic condition* & Basic condition* \\
\hline C (untreated cotton) & - & - & - & - \\
\hline C8a & + & & + & + \\
\hline C8b & + & & + & + \\
\hline C8Ba & + & + & + & \\
\hline C8Bb & + & + & & \\
\hline *Acidic or basic stock solutions of $8 H Q$ were used. \\
Source: Authors
\end{tabular}

Application of Antibacterial Agents on Cotton Samples:

Firstly the samples were scoured in order to remove waxes and fats. (Scouring is a pre-treatment. Scouring process: $5 \mathrm{~g} / \mathrm{L} \mathrm{NaOH}-3 \mathrm{~g} / \mathrm{LNa}_{2} \mathrm{CO}_{3}-2 \mathrm{~g} / \mathrm{L}$ nonionic wetting agent $-90^{\circ} \mathrm{C}, 60 \mathrm{~min}$. $\mathrm{pH}=12$ ). Then they were treated with the treatment solution in accordance with the following method. Briefly, the scoured cotton fabric samples were immersed in the warm treatment solution. Temperature of the bath with F:L (fabric to liquor ratio) of $1: 20$ was raised to $60^{\circ} \mathrm{C}$ and the process was continued for 30 minutes with constant stirring. The treated cotton samples were then washed with tap water in order to remove any non-bonded chemicals.

Determination of Antibacterial Properties:

The ISO 20645:2004 method was mimicked to determine the antibacterial properties of the cotton samples (ISO 20645, 2004). The bacterial strains which were stored at $80^{\circ} \mathrm{C}$ were precultured in $10 \mathrm{ml}$ of broth medium in a shaking incubator at $37 \pm 1^{\circ} \mathrm{C}$ for $16 \mathrm{~h}$. The broth media used were Nutrient Broth for E. coli and Trypticase Soy Broth for S. aureus. $10 \mu \mathrm{l}$ of the precultures were inoculated into the desired volume of fresh broth media. Approximate CFU numbers were estimated from the $\mathrm{OD}_{600}$ measurements and the bacterial culture was produced by incubating at $37 \pm 1{ }^{\circ} \mathrm{C}$ until the bacteria concentration reached $10^{8} \mathrm{CFU} / \mathrm{ml}$ (Cheng et al., 2009).

In order to test the antibacterial properties of the samples, two-layered soft agar plates were prepared. Both the lower and upper layers were composed of soft agar media including $10 \mathrm{~g}$ of agar in the broth media described above. The lower layer was $10 \mathrm{ml}$ in volume and did not contain any bacteria. The upper layer was $5 \mathrm{ml}$ in volume and contained $100 \mu \mathrm{l}$ of the bacterial culture.

Each cotton sample to be tested was cut into $30 \mathrm{~mm} \times 30 \mathrm{~mm}$ squares. Then, each sample was placed onto petri dishes containing the soft agar medium and incubated at $37 \pm 1^{\circ} \mathrm{C}$ for 24 hours. The experiments were performed and repeated three times. The average diameter of the inhibition zones was calculated using equation (1) (Kimiran Erdem \& Sanli Yurudu, 2008):

$$
A=(B-C) / 2
$$


where $\mathrm{A}$ is the average diameter of the clear inhibition zone in $\mathrm{mm}, \mathrm{B}$ is the total diameter of the inhibition zone including the cotton sample and clear zone in $\mathrm{mm}$, and $\mathrm{C}$ is the length of the cotton sample to be tested.

The antibacterial activities of the samples were tested before and after washing (5 times) which were performed by using the Standard Test Method ISO 105-C06 A1S, (2010). The A1S washing test was carried out at $40^{\circ} \mathrm{C}$ for $30 \mathrm{~min}$ in a $150 \mathrm{ml}$ soap solution $(4 \mathrm{~g} / \mathrm{L})$ containing 10 steel balls. After washing, the samples were rinsed in deionized cold water, dried in the open air, and then tested for antibacterial properties as mentioned above.

\section{Results and Discussions}

When the FT-IR spectra was investigated (Figure 1), all the samples had a signal at $896 \mathrm{~cm}^{-1}$ and $1160-1170 \mathrm{~cm}^{-1}$ belonging to the $\beta$-glycosidic linkage of cellulose, the main structure of cotton (Tezcan \& Atıc1, 2017). The $\beta$-glycosidic linkage is related to the integrity of cellulose fibers and is very important for cotton. This signal didn't change in all the samples of this research. Therefore, cellulose integrity seems unaffected during the treatments. However, the signals specific to boron and $8 \mathrm{HQ}$ were masked by the signals associated with cotton, therefore the bonds between $8 \mathrm{HQ}$, boron and cotton could not be confirmed by the FT-IR spectra.

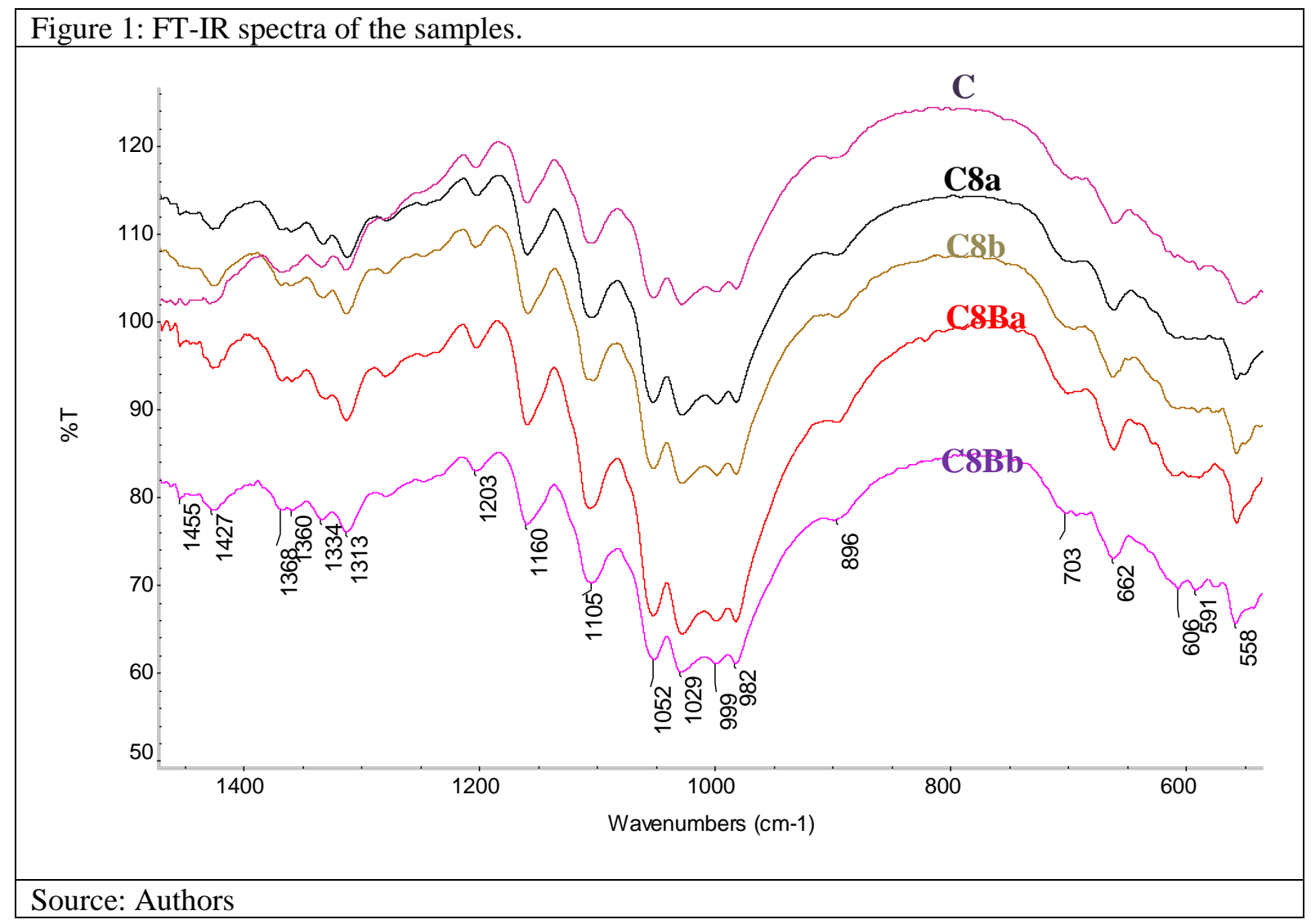

The treated and untreated cotton samples were characterized with SEM imaging as shown in Figure 2 and Table 2. The $\mathrm{C} 8 \mathrm{Ba}$ and $\mathrm{C} 8 \mathrm{Bb}$ samples had more micro cracks and rough structures than the $\mathrm{C} 8 \mathrm{a}$ and C8b samples. Furthermore, it was observed that the cotton fiber structure was adversely affected under acidic conditions compared to alkaline conditions.

The distribution of the treatment chemicals on the sample surface was investigated using SEM/EDX imaging (Table 2). It was confirmed that boron homogeneously distributed on the cotton surface after the treatment processes. Elemental distribution results from EDX showed that B/C and N/C ratios were close to each other at both acidic and alkaline treatment conditions. 


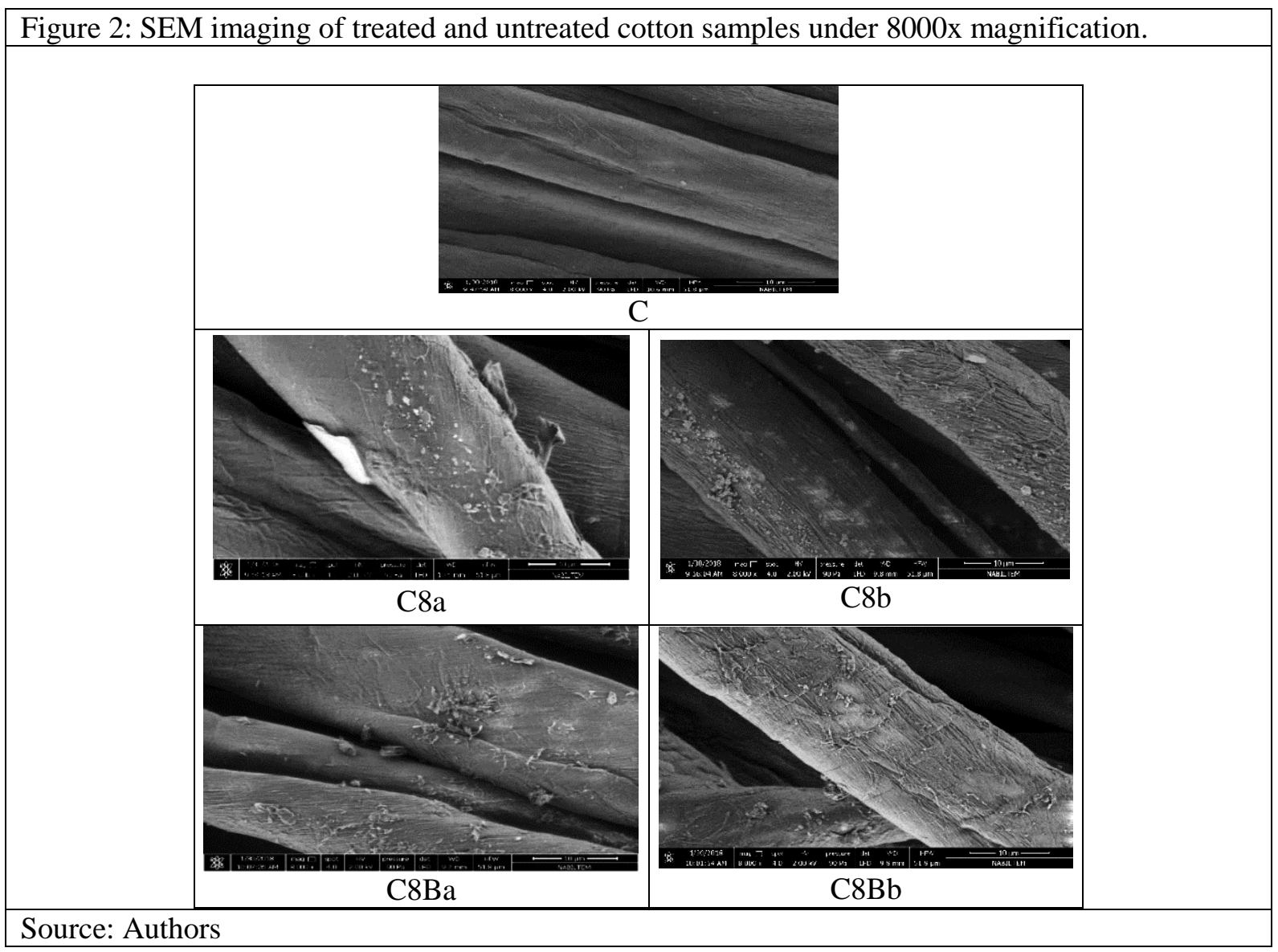

\begin{tabular}{|c|c|c|c|c|}
\hline Samples & $\begin{array}{c}\mathrm{B} / \mathrm{C} \\
(\mathrm{mol} / \mathrm{mol})\end{array}$ & $\begin{array}{l}\text { EDX Mapping Showing } \\
\quad \text { Boron (2000x) } \\
\begin{array}{l}\mathrm{B} \mathrm{K} \quad 20 \mu \mathrm{m} \\
2000 \mathrm{x} \quad \mathrm{kV}: 20.0 \text { Tilt: } 0\end{array} \\
\end{array}$ & $\begin{array}{c}\mathrm{N} / \mathrm{C} \\
(\mathrm{mol} / \mathrm{mol})\end{array}$ & $\begin{array}{l}\text { EDX Mapping Showing } \\
\text { Nitrogen (2000x) } \\
\mathrm{N} \mathrm{K} \longmapsto 20 \mu \mathrm{m} \\
2000 \mathrm{x} \quad \mathrm{kV}: 20.0 \text { Tilt: } 0\end{array}$ \\
\hline $\mathrm{C} 8 \mathrm{a}$ & - & - & 0.14 & \\
\hline $\mathrm{C} 8 \mathrm{~b}$ & - & - & 0.12 & \\
\hline $\mathrm{C} 8 \mathrm{Ba}$ & 1.14 & & 0.13 & \\
\hline $\mathrm{C} 8 \mathrm{Bb}$ & 1.12 & & 0.11 & \\
\hline
\end{tabular}

Source: Authors 
The antibacterial properties of the treated samples against S. aureus (gram-positive) and E. coli (gram-negative) bacteria were measured before and after 5 cycles of washing as presented in Table 3. Untreated cotton samples (C) were prepared for comparison.

Table 3: Zone diameters $(\mathrm{mm})$ created by the cotton samples treated with $8 \mathrm{HQ}$ and BX

\begin{tabular}{|c|c|c|c|c|}
\hline Sample & \multicolumn{2}{|c|}{ S. Aureus (Gram Positive) } & \multicolumn{2}{c|}{ E. Coli (Gram Negative) } \\
\hline & Before washing & After washing & Before washing & After washing \\
\hline C & 0 & 0 & 0 & 0 \\
\hline C8a & 12 & 7 & 10 & 5 \\
\hline C8b & 18 & 11 & 15 & 9 \\
\hline C8Ba & 21 & 12 & 15 & 8 \\
\hline C8Bb & 23 & 16 & 19 & 13 \\
\hline Source: Authors
\end{tabular}

When the results shown in Table 3 was examined, the untreated cotton sample (C) was not effective against any of the bacteria tested. In comparison, the 8HQ and BX treated samples (C8Ba and $\mathrm{C} 8 \mathrm{Bb}$ ) showed antibacterial activity against all the bacteria tested and they were more antibacterial than the samples treated only with $8 \mathrm{HQ}(\mathrm{C} 8 \mathrm{a}$ and $\mathrm{C} 8 \mathrm{~b})$.

The $8 \mathrm{HQ}$ and borax treatment under alkaline conditions produced greater antibacterial properties than acidic conditions and the highest zone diameters were observed in the $\mathrm{C} 8 \mathrm{Bb}$ sample, which exhibited a $23 \mathrm{~mm}$ zone against $S$. aureus and a $19 \mathrm{~mm}$ zone against $E$. coli before washing. It was observed that the $8 \mathrm{HB}$ solution was more effective against gram-positive bacteria. 5 cycles of washing decreased the antibacterial properties of all the samples by about $40-50 \%$, but all the samples were still antibacterial after washing.

When evaluated with SEM results (Figure 2), the 8HB treatment of the cotton samples should be applied under alkaline conditions to avoid damaging the cotton fibers and to increase the antibacterial properties.

\section{Conclusion}

The aim of this study was to give antibacterial properties to cotton samples by applying 8 -hydroxyquinoline (8HQ) and borax $(8 \mathrm{HB})$ solutions in acidic and alkaline conditions. Untreated cotton fabrics were used as the control group. The antibacterial properties of the samples were investigated against Gram-negative (E. coli) and Gram-positive (S. aureus) bacteria.

The untreated cotton samples showed no antibacterial properties against any of the tested bacteria while the $8 \mathrm{HB}$ treated cotton samples showed the highest antibacterial effect against all the tested bacteria, especially when applied under alkaline conditions. After 5 cycles of washing, the antibacterial activities decreased about $40-50 \%$, but the $8 \mathrm{HB}$ treated samples were still effective against all the bacteria tested. It was observed that the antibacterial effect of 8HQ treated cotton fabrics increased in the presence of borax. In view of these results, it was thought that the 8HQ and borax containing formulations can be good candidates for application in the medical textiles sector.

\section{References}

Block, S. S. (2012). Application and use of fungicides as industrial preservatives. (Torgeson, Dewayne, Ed.), Agricultural and Industrial Applications Environmental Interactions: An Advanced Treatise (pp. 379-416). Elsevier.

Buyukakinci, BY., Sökmen, N., Bayender, B. (2016). Effect of Sodium Borohydride on Microwave Assisted Reductive Cleaning of Dyed Polyester Fabrics. Asian Journal of Chemistry, 28, (12), 2752-2754.

Buyukakinci, BY., Yılmaz, A. (2017). Investigation of Boric acid and Sodium borate Effect on Flame Retardancy of Cotton and Polyester Fabrics. Asian Journal of Chemistry, (4), 893-895.

Cheng, C.-L., Sun, D.-S., Chu, W.-C., Tseng, Y.-H., Ho, H.-C., Wang, J.-B., et al. (2009). The effects of the bacterial interaction with visible-light responsive titania photocatalyst on the bactericidal performance. Journal of Biomedical Science, 16(1), 7.

De Seta, F., Schmidt, M., Vu, B., Essmann, M. \& Larsen, B. (2009). Antifungal mechanisms supporting boric acid therapy of Candida vaginitis. Journal of Antimicrobial Chemotherapy, 63(2), 325-336.

Gao, Y. \& Cranston, R. (2008). Recent advances in antimicrobial treatments of textiles. Textile Research Journal, 78(1), 6072. 
ISO 105-C06 A1S. (2010). Tests for colour fastness - Part C06: Colour fastness to domestic and commercial laundering. Technical Committee.

ISO 20645. (2004). Determination of antibacterial activity-agar diffusion plate test. Technical Committee CEN. TC, 248.

Kimiran Erdem, A. \& Sanli Yurudu, N. O. (2008). The evaluation of antibacterial activity of fabrics impregnated with dimethyltetradecyl (3-(trimethoxysilyl) propyl) ammonium chloride. IUFS Journal of Biology, 67(2), 115-122.

Klemencic, D., Tomsic, B., Kovac, F. \& Simoncic, B. (2012). Antimicrobial cotton fibres prepared by in situ synthesis of $\mathrm{AgCl}$ into a silica matrix. Cellulose, 19(5), 1715-1729.

Prachayasittikul, V., Prachayasittikul, S., Ruchirawat, S. \& Prachayasittikul, V. (2013). 8-Hydroxyquinolines: a review of their metal chelating properties and medicinal applications. Drug Design, Development and Therapy, 7, 1157-1178.

Reijnders, L. (2006). Cleaner nanotechnology and hazard reduction of manufactured nanoparticles. Journal of Cleaner Production, 14(2), 124-133.

Short, B. R., Vargas, M. A., Thomas, J. C., O'hanlon, S. \& Enright, M. C. (2005). In vitro activity of a novel compound, the metal ion chelating agent $\mathrm{AQ}+$, against clinical isolates of Staphylococcus aureus. Journal of Antimicrobial Chemotherapy, 57(1), 104-109.

Srisung, S., Suksrichavalit, T., Prachayasittikul, S., Ruchirawat, S. \& Prachayasittikul, V. (2013). Antimicrobial activity of 8hydroxyquinoline and transition metal complexes. International Journal of Pharmacology, 9(2), 170-175.

Tezcan, E. \& Atıc1, O. G. (2017). A new method for recovery of cellulose from lignocellulosic bio-waste: Pile processing. Waste Management, 70, 181-188.

Xie, F. \& Peng, F. (2017). Anti-prostate cancer activity of 8-hydroxyquinoline-2-carboxaldehyde-thiosemicarbazide copper complexes by fluorescent microscopic imaging. Journal of Fluorescence, 27(6), 1937-1941.

Xu, H., Chen, W., Zhan, P., Liu, X. \& others. (2015). 8-Hydroxyquinoline: a privileged structure with a broad-ranging pharmacological potential. MedChem Comm, 6(1), 61-74.

Yilmaz, M. T. (2012). Minimum inhibitory and minimum bactericidal concentrations of boron compounds against several bacterial strains. Turkish Journal of Medical Sciences, 42(Sup. 2), 1423-1429. 